\title{
Vertical characteristics of cyclonic tracks over the eastern Mediterranean during the cold period of the year
}

\author{
Flocas H.A ${ }^{1}$, Kountouris P. ${ }^{1}$, Kouroutzoglou J. ${ }^{1}$, Hatzaki M. ${ }^{1}$, Keay K. ${ }^{2,3}$, Simmonds I. $^{2}$ \\ ${ }^{1}$ Department of Environmental Physics-Meteorology, Faculty of Physics, University of \\ Athens, Athens, Greece \\ ${ }^{2}$ School of Earth Sciences, University of Melbourne, Victoria, Australia \\ ${ }^{3}$ Bureau of Meteorology, Melbourne, Australia
}

Corresponding author address: Helena A. Flocas, Department of Environmental PhysicsMeteorology, Faculty of Physics, Building PHYS-5, University of Athens, University campus, 15784 Athens Greece, e-mail: efloca@phys.uoa.gr

\begin{abstract}
The vertical structure of surface cyclonic tracks affecting the eastern Mediterranean region is studied on a climatological basis for the cold period of the year. The dataset used is the $1^{\circ} \times 1^{\circ}$ ERA-40 Reanalysis, for a 40-year period (1962-2001). The vertical tracking of surface cyclonic tracks was performed with the aid of the Melbourne University Vertical Tracking Algorithm. It was found that about $83 \%$ of the cyclones were extended up to the $500 \mathrm{hPa}$ level and almost $65 \%$ up to $200 \mathrm{hPa}$ level, implying that the cyclones are in general well organised. The surface tracks that originate within the examined area exhibit the smallest vertical extension, intensity, radius and depth, compared to the cyclones originating in the other sectors. Moreover, the 500hPa counterparts for the above cyclones are mainly located to the north-west or south-west of the surface cyclone position, consistent with the baroclinic character of the Mediterranean cyclones. The zonal (eastward) component of motion predominates at both surface and $500 \mathrm{hPa}$.
\end{abstract}




\section{Introduction}

The eastern Mediterranean, extending between $20^{\circ}$ and $38^{\circ} \mathrm{E}$ and including the Ionian, Aegean and Levantine Seas (see Fig. 1), is an area of great interest with respect to cyclone behaviour, due to its location between subtropics and midlatitudes and also due to its complex topography (HMSO 1962).

Studies related to the cyclonic tracks in the eastern Mediterranean refer to specific types of cyclones, such as frontal cyclones (Flocas 1988) and to specific areas, such as the Aegean Sea and Cyprus (Maheras 1983; Nicolaides et al. 2004), employing synoptic analyses of mean sea level pressure. Furthermore, Alpert et al (1990) and Trigo et al. (1999) depicted characteristics of surface tracks in the eastern Mediterranean, as part of a climatology for the whole Mediterranean region, by employing objective methods.

Recently, Flocas et al. (2010) presented an updated climatology of surface cyclonic tracks passing over the eastern Mediterranean and explored their trends for a period of 40 years with the aid of the Melbourne University cyclone identification and tracking scheme, employing the $2.5^{\circ} \times 2.5^{\circ}$ ERA-40 Reanalysis dataset.

The vertical structure of surface cyclones in the eastern Mediterranean has been examined by Maheras et al. (2002) and Trigo et al. (2002), in their attempt to investigate characteristics of Mediterranean cyclones in regions of enhanced cyclonic activity, without performing vertical tracking. More recently, Campins et al. (2011) examined vertical characteristics of Mediterranean cyclones with the aid of a tracking scheme and $1.125^{\circ} \mathrm{X}$ $1.125^{\circ}$ resolution datasets, including the eastern Mediterranean.

Despite the considerable research that has been performed on surface cyclonic tracks in the Mediterranean, to our knowledge, there are no studies referring to the vertical characteristics of surface tracks passing over the eastern Mediterranean, using a fully objective method. In line with these considerations, the aim of this study is: a) to perform a climatology of the vertical profile and organization of cyclonic tracks in the eastern Mediterranean during the cold period of the year, employing an automated vertical tracing 
software with resolution $1^{\circ} \times 1^{\circ}$, and b) to investigate the spatial distribution of dynamic and kinematic characteristics at each isobaric level of cyclonic tracks, such as cyclogenesis, system density, depth, cyclone propagation.

\section{Data and Methodology}

The employed datasets include 6-hourly analyses of mean sea level pressure (MSLP) and geopotential (GH) for $850,700,500,300$ and $200 \mathrm{hPa}$ on a $1^{\circ} \times 1^{\circ}$ regular grid (interpolated from the respective $1.125^{\circ} \times 1.125^{\circ}$ grid through the ECMWF) for the months of the cold months (January, February, March, October, November December) of each year for the period from 1962 to 2001, as derived from the ERA-40 Reanalysis of the ECMWF (Uppala et al. 2005).

The identification and tracking procedure of the surface cyclonic tracks was performed with the aid of the Melbourne University cyclone finding and tracking scheme (hereafter, MS scheme), which is developed in Melbourne University according to the Lagrangian perspective (Murray and Simmonds 1991a; 1991b; Simmonds and Murray 1999; Simmonds et al. 1999). In the MS scheme, a detected surface cyclone is characterized as a closed one if a local maximum of the quasi-geostrophic relative vorticity can be related to a pressure minimum in the vicinity of the laplacian maximum in order to associate the latter with a real low pressure core (Simmonds and Murray 1999). Otherwise, the surface cyclone is recorded as an open one with its centre located at the position of the laplacian maximum.

In the Mediterranean, the MS algorithm was recently employed to study surface cyclones in the eastern basin (Flocas et al. 2010) and explosive cyclones (Kouroutzoglou et al. 2011a; 2011b). In these studies the control parameters of the MS algorithm have been modified in order to better capture the individual characteristics of cyclones in a closed basin with complex topography (see Appendix 1).

The cyclonic tracks are examined during the cold months of each year, because they appear their maximum frequency during this period of the year (Flocas et al. 2010). The eastern Mediterranean is represented by the shaded area in Fig. 1. An eastern Mediterranean 
track is considered as every surface track entering the eastern Mediterranean basin having the form of a closed cyclone for at least one time step (6 hours). For each cold month, the frequency of tracks entering the eastern Mediterranean was determined. Then, the frequency of tracks for each month was calculated according to their origin domain, which is represented by the first step of the track. Specifically, six sectors were defined (see Fig. 1): a) the North-western (NW) sector, b) the Western (W) sector, c) the South-western (SW) sector, d) the North-eastern (NE) sector, e) the northern part of the examined area of eastern Mediterranean (EM1), f) the southern part of the examined area (EM2). Based on this classification, the examined area for the eastern Mediterranean is represented by the sectors EM1 and EM2, and hereafter will be referred to as EM12 area.

After the identification of the surface cyclones, their vertical extension is defined by applying an updated and improved version of the Vertical Tracing Software (hereafter, VTS) of the MS algorithm (see Kouroutzoglou et al. 2012). Following a two-step procedure, initially cyclone centres are separately detected at each selected isobaric level and for each track step from ordinary surface cyclogenesis to cyclolysis. The specification of the set of the algorithm parameters at each isobaric level is summarised in Appendix 1. The next step of the VTS is the connection between a pair of neighbouring levels starting from the surface. It is convenient to regard the initial lower level in the sequence as the 'base' set of tracks. Each track point of a track in the base set is attempted to be matched to a track point at the next upper level. The output from this process is a 'trace' file that contains the matching status of each track point in the base set. A flag is set if there is no match i.e. the cyclone does not extend to the upper level, otherwise the track information for the matched cyclone will be listed. This procedure is repeated until the highest level is processed i.e. $200 \mathrm{hPa}$ in our study.

The output trace file contains information on the vertical matching of cyclones from the base level to the highest level, i.e. from mean sea level to $200 \mathrm{hPa}$. If a cyclone appears at the highest level, it is implied that it has been matched through each one of the intermediate levels. At each tracing stage, the output trace file contains the new link in the matching chain 
which has a one-to-one correspondence with the tracks at the initial lower level. Hence, each trace file contains the characteristics of the cyclones at the new (upper) level.

The search for the connection between a cyclone at the lower level and a cyclone at the upper level is performed inside a circular domain centred at the lower level cyclone centre. A fixed search radius is preferred and the values of the radius were selected, following the synoptic experience on the vertical separation of Mediterranean cyclones (see Appendix 1). If more than one candidate is found within the searching domain of an isobaric level, a weighting is given to the factors controlling the separation, i.e. the depth difference and the type difference (closed-open) between the lower and the upper level cyclone, according to the equation:

$$
\min \left[C_{\text {match }}(\text { pair })\right]=\left(w_{1} \cdot p_{1}+w_{2} \cdot p_{2}\right) w
$$

where $p_{1}$ is the ranked pair separation ( $<$ search radius), $p_{2}$ is the ranked pair depth difference, $w_{1}$ and $w_{2}$ are the weighting factors controlling the importance of the pair separation depth difference imposing the constraint $w_{1}+w_{2}=1, w$ is the weighting factor for the difference in cyclone type: if the upper and lower cyclones have the same type, i.e. both closed or open, then $w=1-w_{3}$, otherwise $w=w_{3}$. All factors $\left(w_{1}, w_{2}, w_{3}\right)$ take values in the range $[0,1]$. In our case, sensitivity tests resulted in employing equal weighting to all factors $w_{1}=w_{2}=w_{3}=0.5$.

It should be noted that although the VTS identifies the counterpart of the surface cyclone after the initiation of the surface cyclogenesis, the complete track of the upper level cyclone is constructed from its cyclogenesis track point to the cyclolysis point, allowing the examination of the "history" of the upper level cyclone, even if the cyclogenesis initiates at the upper levels. The tilting of the surface cyclones with respect to the $500 \mathrm{hPa}$ counterpart is calculated in terms of the compass direction and the respective distance. More specifically, the calculation of the tilting comprises grid point percentages of 500hPa cyclones, representing eight compass bins (NNE, ENE, ESE, SSE, SSW, WSW, WNW and NNW) in relation to the surface cyclone location (Fig. 2), taking into account only the period that the respective tracks remain in the target area EM12 or accordingly the surface track steps within the EM12. 
For each sector, the mean values of the following dynamic and kinematic parameters of the surface cyclonic tracks are calculated for the period that they remain within the EM12 area and for each isobaric level: a) the cyclone radius $R$ (in degrees of latitude) (Lim and Simmonds 2007), b) the laplacian of the central pressure $\nabla^{2} P$ (in hPa deg.lat ${ }^{-2}$ for the surface cyclones and $\mathrm{m}$ deg.lat ${ }^{-2}$ for the upper level cyclones), representing an effective measure of cyclone intensity (Petterssen 1956), c) the cyclone depth $D$ (in hPa and m for the surface and upper level cyclones, respectively) that combines the cyclone size and intensity (Simmonds et al. 1999; Simmonds and Keay 2000; Simmonds and Keay 2009).

\section{Surface track variations}

The classification of the tracks passing through the EM12 area, according to the origin domain during the cold period of the year (Fig. 3) reveals that the greatest number (31\%) originate in the northern part of the examined area (EM1), that is, the Aegean Sea, northern and central Greece, Balkans and Black Sea (see Fig. 1). A remarkable portion (28\%) originates in the EM2 (e.g. the Ionian Sea, the south-eastern Aegean Sea, Crete, Cyprus, and the Levantine Sea).

Apart from these tracks that originate within the examined area (EM1 and EM2), the next most frequent cyclonic tracks originate in the Western sector (16.1\%), which incorporates the Adriatic Sea and parts of the western Mediterranean and the Atlantic. The tracks from North Africa and the Alboran Sea, being attributed to the SW origin sector, comprise the percentage of $14 \%$. A limited number of tracks $(5.6 \%)$ originate in the NW sector, since the NW and EM12 sectors share a very limited border and the NW tracks are found to enter the target area mainly through the $\mathrm{W}$ sector. The tracks originating in the NE sector are also limited in number (4.4\%), being related with cyclones, forming mainly in the northern part of the Balkan Peninsula, eastern Europe and part of the Black Sea.

This frequency distribution of surface cyclone tracks according to their origin domain for the cold period is consistent with the respective results of Flocas et al. (2010) on annual basis 
employing the same datasets, but for lower resolution. The only difference is that the greatest number of cyclonic tracks originate in EM2 on an annual basis rather than in EM1, being attributed to the high frequency of cyclonic tracks of thermal character in EM2 during summer and autumn.

From Fig. 4, it can be seen that the maximum number of cyclonic tracks over the examined area during the cold period is observed in March (17.9\%) and the minimum in February (15.6\%). More specifically, it was found that for EM1 and SW tracks, the greatest number of tracks is favoured in March, for EM2 tracks in October, for NE in January, for NW in November and December, for W in February (not shown).

The geographical distribution of the density (e.g. average number of surface cyclones per unit area) over EM12 (Fig. 5) displays a remarkable maximum over northern Aegean Sea, in accordance with the frequency maximum of tracks originating in EM1 (see Fig. 3). Secondary maximum can be found over south-eastern Aegean Sea, between Rhodes and Cyprus, an area that lies in the main branch of the winter cyclones that generate in the Gulf of Genoa and follow a southerly route (Alpert et al. 1990) and in the path of the cyclones that generate in northern Aegean Sea (Campins et al. 2011). Moreover, both Cyprus and the SE Aegean Sea

are not only influenced by the passage of mobile cyclones, but also constitute centres of cyclogenetic activity, due to enhanced sea fluxes in the lee of Turkish mountains (Shay-El and Alpert 1991; Lolis et al. 2004). The system density is increased over Ionian Sea, which lies along the south-eastward path of cyclones generating in the western Mediterranean, South Italy and along easterly route of the Saharan depressions (Flocas et al. 2010).

\section{Vertical structure}

The VTS examines the vertical extension at each time step of surface cyclonic tracks, from cyclogenesis to cyclolysis. A cyclonic system is considered to extend vertically to an isobaric level, if one, at least, of its track steps was identified at the respective level. All cyclonic systems that can be traced in the vertical, up to the $300 \mathrm{hPa}$ level, were considered as vertically 
"well organized" (or deep) systems, contrary to "non-well organized" (or shallow) systems that reach up to $700 \mathrm{hPa}$ (Campins et al. 2011).

The calculation of the percentage of surface systems being traced at each one of the five selected isobaric levels (Table 1), showed that $82.8 \%$ of the cyclones were extended up to the $500 \mathrm{hPa}$ and $64.8 \%$ up to $200 \mathrm{hPa}$. As can be seen in Table 2, the vertical structure of surface cyclones does not present remarkable inter-monthly variations during the cold period. In January, the greatest percentages of surface cyclones extend up $500 \mathrm{hPa}(86.7 \%), 300 \mathrm{hPa}$ (75.6\%) and $200 \mathrm{hPa}(64.4 \%)$, as compared to the other months.

Table 3 presents the percentage of the surface cyclones that reach each isobaric level, according to their origin domain. It can be seen that the EM1 and EM2 tracks exhibit the smallest vertical extension, compared to those originating in the other sectors, since $64.7 \%$ and $67.9 \%$, respectively, reach up to $300 \mathrm{hPa}$. This could be attributed to the fact that cyclogenesis in the EM12 during winter is a sub-synoptic scale phenomenon that is mainly related with the orographic effect and sea fluxes (Flocas and Karacostas 1996; Maheras et al. 2002). On the contrary, the cyclones originating in the NW and W sectors are characterised by the largest highest extension, since $80.4 \%$ and $74.3 \%$, respectively, reach $200 \mathrm{hPa}$. Consequently, the frequency of organised systems is larger for sectors NW (86.7\%) and W $(82.6 \%)$ and smaller for EM1 (64.7\%) and EM2 (67.9\%).

It is noteworthy that about $20 \%$ of the cyclones originating in the SW sector develop only at the surface and do not even reach the $850 \mathrm{hPa}$. These are relatively shallow systems that generate near the western boundaries of the SW sector with the EM12, between the south Ionian Sea and the Gulf of Syrte, as was demonstrated by the spatial distribution of the SW sector cyclones (not shown). However, the majority of SW cyclones extend throughout the troposphere. More specifically, the 65\% of SW cyclones reach the level of $200 \mathrm{hPa}$. These mainly include extended closed cyclones that generate in the northwest Africa, being supported by upper level cold outbreak and vorticity advection (Prezerakos et al. 1990). 
The construction of the $500 \mathrm{hPa}$ 'full tracks' (from the cyclogenesis to cyclolysis of the $500 \mathrm{hPa}$ cyclone) can result in the calculation of the temporal difference between the time of surface maximum depth and the time of 500hPa maximum depth (see Table 4). It becomes evident that for the majority of the surface cyclones and for all sectors, the surface maximum depth is attained before the $500 \mathrm{hPa}$ counterpart, implying that the deepening is forced not only by the upper levels, rather by the surface processes. This is more evident for cyclones originating in the $\mathrm{W}$ sector and can be possibly attributed to the fact that cyclones originating in the western Mediterranean are mainly related to low level cold outbreaks from north-west during the cold period of the year or sea surface fluxes, leading to large cyclonic deepening inside EM12 (Campins et al. 2011; Kouroutzoglou et al. 2011a; 2011b).

According to Table 5, for the vast majority (86.2\%) of cyclones passing over EM12, the $500 \mathrm{hPa}$ counterparts are mainly located to the north-west (NNW or WNW) or south-west (SSW or WSW) of the surface cyclone position. More specifically, almost $16.8 \%$ of the surface cyclones are associated with $500 \mathrm{hPa}$ counterparts in the WNW sector, $31.7 \%$ in the NNW sector, $16.8 \%$ in the WSW sector and $9.2 \%$ in the SSW sector. These results support the baroclinic character of EM cyclones and are in good accordance to the findings of Maheras et al. (2002), who found a negative slope of the vertical profile of the negative geopotential anomalies for South Italy and Cyprus cyclones during winter. The cyclones that exhibit an eastward tilt with height (13.7\%) are mainly located in the area of Cyprus and can be explained by the fact that this area is the eastern edge of the preferable paths of Mediterranean cyclones penetrating EM12 from the west (Alpert et al. 1990), where surface cyclones lose their westward tilting and weakened (Flocas et al. 2010).

\section{Dynamic and kinematic parameters}

Figure 6 presents the vertical profile of mean intensity, radius and depth of cyclones for the part of each relevant track within the target area EM12 and for each origin sector. It can be seen that for all sectors the mean intensity decreases with height up to $700 \mathrm{hPa}$ and then 
increases up to $300 \mathrm{hPa}$, where it peaks and then decreases again (Fig. 6a), implying that the cyclones are more intense at upper levels as compared to the lower ones. The mean radius increases with height up to $300 \mathrm{hPa}$, attaining its maximum value and then decreases (Fig. 6b). Consequently, Fig. $6 \mathrm{c}$ shows the mean depth profile, being characterized by almost constant values in the lower troposphere up to $700 \mathrm{hPa}$. At $500 \mathrm{hPa}$, the mean depth increases substantially and peaks at $300 \mathrm{hPa}$ and then decreases.

In general, it becomes evident that the cyclones originating within EM12 are characterized by smaller intensity, radius and depth, as compared with those originating outside the target area. Furthermore, the EM1 cyclones are more intense and deeper than EM2 cyclones at all levels, despite their smaller scale. Similarly to Flocas et al. (2010), the SW, W, NW tracks are characterized by maximum depth at the lower levels (Fig. 6c). However, it is demonstrated that at the upper levels these tracks differentiate with respect to their depth. The north-westerly (NW) tracks are characterized by the highest intensity at all levels (Fig. 6a) and the highest depth at the upper levels (Fig. 6c). The south-westerly (SW) tracks appear larger mean radius at the lower levels (Fig. 6b) and consequently increased depth while their depth decreases notably at higher levels (Fig. 6c). For the NE tracks, the depth increases considerably above $500 \mathrm{hPa}$, reaching the depth values of the NW and $\mathrm{W}$ tracks and exceeding those of SW tracks, following similar profiles of intensity and radius.

From the geographical distribution of the mean depth for the tracks passing over EM12 at surface and $500 \mathrm{hPa}$ becomes evident that the surface tracks have higher depth outside the examined area, and especially over the western Mediterranean and south Italy (Fig. 7). Within the target area, peak values form over the south-eastern Aegean Sea, being associated with increased sea surface fluxes (Shay-El and Alpert 1991). At $500 \mathrm{hPa}$, higher depth values are found compared to the surface, in accordance to Fig. 6c. However, the maximum depth of cyclonic tracks is observed within the examined area and in its western boundary, i.e. in south Italy and the Ionian Sea. 
The geographical distribution of the average cyclogenesis, namely the number of new systems appearing per unit area and per unit time (Keable et al. 2002), in the examined area shows that a clear surface maximum is formed over the Aegean Sea (Fig. 8a), further confirming that the majority of tracks generate within EM12, as previously discussed. Although the surface cyclones originate in the target area, their $500 \mathrm{hPa}$ counterparts generate mainly outside it and specifically in the western Mediterranean, with peak frequency in the Gulf of Genoa (Fig. 8b), suggesting the baroclinic character of the EM cyclones, consistent with Trigo et al. (2002). Moreover, this finding complies with Prezerakos and Flocas (1997) for cyclones forming over the Aegean Sea. A secondary maximum of $500 \mathrm{hPa}$ cyclogenesis can be found over the northern Aegean and Turkey, more likely associated with surface Cyprus cyclones (Maheras et al. 2002).

The average zonal (meridional) cyclone fluxes represent the average number of cyclones crossing eastwards (northwards) across a north-south (west-east) area. Positive values denote a northward and eastward motion, respectively. According to Fig. 9a, surface cyclones in the whole examined area EM12 prefer to move eastwards with maximum zonal fluxes over the southern Aegean and the Black Sea. Moreover, from Fig. 10a it can be seen that they are characterized by a substantial southward component in EM2 and the whole Aegean Sea, peaking over Crete. On the contrary, in the EM1 a northward component predominates with maximum over the Black Sea (Fig. 10a). In addition, the relative importance of zonal and meridional fluxes is further investigated through the absolute ratio of the meridional to the zonal fluxes (Fig. 11a), denoting the areas where meridional or zonal fluxes are greater. As can be seen zonal fluxes predominate in the whole examined area, except the northern boundaries (Balkans) and southern boundaries (northern African coast), where the meridional component is stronger.

At $500 \mathrm{hPa}$, the eastward component prevails similarly to the surface, which, however, extends in the northwest of the examined area, over the Adriatic Sea and Italy (Fig. 9b), consistent with the above mentioned baroclinic character of the cyclones. Maximum zonal 
fluxes form over the Adriatic Sea and the eastern boundary of EM2. From Fig. 11b, it becomes evident that the zonal component is predominant over the meridional in the whole area. On the other hand, the distribution of meridional fluxes at $500 \mathrm{hPa}$ (Fig. 10b) is completely different as compared to the surface (see Fig. 10a): the southward component prevails in the whole examined area, extending to the west where they maximized over Italy, confirming the movement of $500 \mathrm{hPa}$ cyclones from the northwest (Karacostas and Flocas 1983; Prezerakos and Flocas 1996; Prezerakos et al. 1999).

\section{Conclusions}

In this study the main features of the vertical profile of the cold period cyclonic tracks affecting the eastern Mediterranean region have been explored for a period of 40 years (19622001) with the aid of the Melbourne University cyclone tracking algorithm and a $1^{\circ} \mathrm{x} 1^{\circ}$ resolution dataset.

The classification of the tracks according to their origin domain has shown that the

majority (59\%) originate within the examined area itself, as was also found in previous study for the cyclonic tracks on an annual basis but with lower resolution. However, contrasting to the results of that study, the cyclonic tracks during the cold period originate mainly in the northern part of the EM, including Greece, the Aegean Sea, Turkey and the Black Sea.

The next most common cyclonic tracks originate in the Western sector, which incorporates the Adriatic Sea and parts of the western Mediterranean and the Atlantic. The maximum number of surface cyclonic tracks is observed in March (17.9\%). The maximum number for each origin sector occurs in different months, reflecting different vertical structure and mechanisms of cyclones according to their origin domain.

The vertical tracing demonstrated that $83 \%$ of the cyclones extend up to the $500 \mathrm{hPa}$ and $65 \%$ up to $200 \mathrm{hPa}$, implying that the cyclones are generally well organised. This vertical structure does not present remarkable inter-monthly variations during the cold period. 
With respect to their origin sector, the surface tracks that originate in EM1 and EM2 areas exhibit the smallest vertical extension, compared to the cyclones originating in the other sectors, and therefore comprise the greater frequency of shallow cyclones.

For the majority of the surface cyclones and for all sectors, the surface maximum depth is attained before the $500 \mathrm{hPa}$ counterpart. This is more evident for cyclones originating in the W sector. It was found that in the vast majority (about $86 \%$ ) of cyclones passing over eastern Mediterranean, the $500 \mathrm{hPa}$ counterparts are mainly located to the north-west (NNW or WNW) or south-west (SSW or WSW) of the surface cyclone position.

In general, it can be seen that for all sectors the cyclones are more intense at the upper levels compared to the lower ones. Furthermore, the cyclones originating within EM12 are characterized by smaller intensity, radius and depth, compared to those originating outside the target area. More specifically, the EM1 cyclones are more intense and deeper than EM2 cyclones at all levels, despite their smaller scale. The north-westerly (NW) tracks are characterized by the highest intensity at all levels and the highest depth at the upper levels.

Although the surface cyclones originate in EM12, their $500 \mathrm{hPa}$ counterparts generate mainly outside the target area and specifically in the western Mediterranean, with peak frequency in the Gulf of Genoa, suggesting the baroclinic character of the EM cyclones.

The surface cyclones passing over eastern Mediterranean prefer to move eastwards, with a southward component in the southern part of the examined area and a northward in the northern part. At $500 \mathrm{hpa}$, the zonal component predominates over the meridional, while the cyclones prefer to move south-eastwards.

The vertical tracking algorithm of the MS has proved to be a very valuable tool for examining the vertical structure of cyclonic tracks in a smaller scale inland sea with complex topography, such as the Mediterranean. Moreover, it has been used to generate an extended climatology of vertical characteristics of the eastern Mediterranean cyclonic tracks that has not been performed in the past. The results of this study verified results obtained in previous studies based on limited number of cyclones in the eastern Mediterranean or on composite 
anomalies of the Mediterranean cyclones in specific cyclogenetic areas. In this sense, the study has revealed valuable additional insights related to cyclone structure, kinematics and dynamics and will help in investigating the physical processes associated with climate of the eastern Mediterranean.

Acknowledgment: M. Hatzaki's contribution to this work was financially supported by the Greek Sate Scholarships foundation, through the Post Doctoral Research Program.

\section{References}

Alpert P, Neeman BU, Shay-El Y (1990) Intermonthly variability of cyclone tracks in the Mediterranean. J Clim 3:1474-1478. doi:10.1175/1520-0442(1990)003<1474:IVOCTI> 2.0.CO;2

Campins J, Genovés A, Picornell MA, Jansà A (2011) Climatology of Mediterranean cyclones using the ERA-40 dataset. Int J Climatol 31:1596-1614. doi:10.1002/joc.2183

Flocas A (1988) Frontal depressions over the Mediterranean Sea and Central Southern Europe. Méditerranée 4:43-52.

Flocas HA, Karacostas TS (1996) Cyclogenesis over the Aegean Sea: identification and synoptic categories. Meteorol Appl 3:53-61. doi: 10.1002/met.5060030106

Flocas HA, Simmonds I, Kouroutzoglou J, Kevin K, Hatzaki M, Bricolas V, Asimakopoulos D (2010) On cyclonic tracks over the eastern Mediterranean. J Clim 23:5243-5257. doi:10.1175/2010Jcli3426.1

HMSO (1962) Weather in the Mediterranean I: General Meteorology. 2d ed. Her Majesty's Stationery Office, $362 \mathrm{pp}$.

Karacostas TS, Flocas AA (1983) The development of the "bomb" over the Mediterranean area. La Meteorologie, Actes de la conference "eau verte" 34:351358. 
Keable M, Simmonds I, Keay K (2002) Distribution and temporal variability of $500 \mathrm{hPa}$ cyclone characteristics in the Southern Hemisphere. Int J Climatol 22:131-150. doi:10.1002/joc.728

Kouroutzoglou J, Flocas HA, Simmonds I, Keay K, Hatzaki M (2011a) Climatological aspects of explosive cyclones in the Mediterranean. Int J Climatol 31:1785-1802, doi:10.1002/joc.2203

Kouroutzoglou J, Flocas HA, Simmonds I, Keay K, Hatzaki M (2011b) Assessing characteristics of Mediterranean explosive cyclones for different data resolution. Theor Appl Climatol 105:263-275. doi:10.1007/s00704-010-0390-8

Kouroutzoglou J, Flocas HA, Keay K, Simmonds I, Hatzaki M (2012): On the vertical structure of Mediterranean explosive cyclones. Theor Appl Climatol doi:10.1007/s00704012-0620-3 (online first)

Lim E-P, Simmonds I (2007) Southern hemisphere winter extratropical cyclone characteristics and vertical organization observed with the ERA-40 data in 1979-2001. J Clim 20:2675-2690. doi:10.1175/JCLI4135.1

Lolis CJ, Bartzokas A, Katsoulis BD (2004) Relation between sensible and latent heat fluxes in the Mediterranean and precipitation in the Greek area during winter. Int J Climatol 24:1803-1816. doi:10.1002/joc. 1112

Maheras P (1983) Les types de temps dépressionnaires perturbés au-dessus de la mer Egée. Rivista Meteorol Aeron 43:23-30.

Maheras P, Flocas HA, Anagnostopoulou C, Patrikas I (2002) On the vertical structure of composite surface cyclones in the Mediterranean region. Theor Appl Climatol 71:199217. doi:10.1007/s007040200005

Murray RJ, Simmonds I (1991a) A numerical scheme for tracking cyclone centres from digital data. Part II: Application to January and July general circulation model simulations. Aust Meteorol Mag 39:167-180. 
Murray RJ, Simmonds I, (1991b) A numerical scheme for tracking cyclone centres from digital data. Part I: Development and operation of the scheme. Aust Meteorol Mag 39:155166.

Nicolaides K, Michaelides S, Karacostas T (2004) Statistical characteristics of the cold season depressions over the area of Cyprus. Meteorol J 7:61-66.

Petterssen S (1956) Motion and motion systems. Vol. 1. Weather analysis and forecasting. 2nd edn. McGraw-Hill, New York.

Prezerakos NG, Flocas HA (1996) The formation of a dynamically unstable ridge at 500hPa as a precursor of surface cyclogenesis in the central Mediterranean. Meteorol Appl 3:101111. doi:10.1002/met.5060030201

Prezerakos NG, Flocas HA (1997) The role of an upper developing diffluent trough in central Mediterranean surface cyclogenesis. Meteorol Z 6:108-119.

Prezerakos NG, Michaelides SC, Vlassi AS (1990) Atmospheric synoptic conditions associated with the initiation of north-west African depressions. Int J Meteorol 10:711-729. doi: $10.1002 /$ joc.3370100706

Prezerakos NG, Flocas HA, Michaelides SC (1999) Upper tropospheric downstream development leading to surface cyclogenesis in the central Mediterranean. Meteorol Appl 6:1-10. doi:10.1017/S1350482799001218

Shay-El Y, Alpert P (1991) A diagnostic study of winter diabatic heating in the Mediterranean in relation to cyclones. Q J R Meteorol Soc 117:715-747. doi:10.1256/smsqj.50003

Simmonds I, Murray RJ (1999) Southern extratropical cyclone behavior in ECMWF analyses during the FROST special observing periods. Weather Forecast 14:878-891. doi:10.1175/1520-0434

Simmonds I, Keay K (2000) Mean Southern Hemisphere extratropical cyclone behavior in the 40-year NCEP-NCAR reanalysis. J Clim 13:873-885. doi:10.1175/1520-0442 
Simmonds I, Keay K (2009) Extraordinary September Arctic sea ice reductions and their relationships with storm behavior over 1979-2008. Geophys Res Lett 39:L9715. doi:10.1029/2009GL039810

Simmonds I, Murray RJ, Leighton RM (1999) A refinement of cyclone tracking methods with data from FROST. Aust Meteorol Mag Special Ed 35-49.

Trigo IF, Davies TD, Bigg GR (1999) Objective climatology of cyclones in the Mediterranean region. J Clim 12:1685-1696. doi:10.1175/1520-0442

Trigo IF, Bigg GR, Davies TD (2002) Climatology of cyclogenesis mechanisms in the Mediterranean. Mon Weather Rev 130:549-569. doi:10.1175/1520-0493

Uppala SM and Coauthors (2005) The ERA-40 Re-analysis. Q J R Meteorol Soc 131:29613012. doi:10.1256/qj.04.176 


\section{List of Figures}

Fig. 1. Geographical chart of the Mediterranean region where the sectors are displayed corresponding to the origin of the tracks (see text for more details). The target area of the eastern Mediterranean is covered by the sectors EM1 and EM2, being referred as EM12 (shaded area).

Fig. 2. Sectors for the searching radius relative to the surface cyclonic centre, according to the tilting routine of the VTS

Fig. 3. Relative frequency (\%) of tracks passing through target area EM12, according to their origin sector

Fig. 4. Relative frequency of the surface tracks passing through the target area EM12 in the cold months of the period 1962-2001.

Fig. 5. Spatial distribution of system density for the cyclonic tracks passing over the eastern Mediterranean at surface and $500 \mathrm{hPa}$; contour interval is 1 and 0.2 cyclones (deg.lat) ${ }^{-2}$ for surface and $500 \mathrm{hPa}$, respectively.

Fig. 6. Vertical profile of mean (a) intensity, (b) radius and (c) depth of cyclonic tracks passing over the eastern Mediterranean for each origin sector. The mean values are calculated for the part of each relevant track within the target area EM12.

Fig. 7. Spatial distribution of depth for the cyclonic tracks passing over the eastern Mediterranean at surface and $500 \mathrm{hPa}$; contour interval is $0.2 \mathrm{hPa}$ for surface and $5 \mathrm{~m}$ for 500 $\mathrm{hPa}$.

Fig. 8. Spatial distribution of cyclogenesis for cyclonic tracks passing over eastern Mediterranean at surface and $500 \mathrm{hPa}$; contour interval is $0.210^{-3}$ cyclones deg.lat $^{-2} \mathrm{day}^{-1}$.

Fig. 9. Spatial distribution of the average zonal fluxes of cyclones at surface and $500 \mathrm{hPa}$; contour interval is 0.0005 and 0.0002 cyclones (deg.lat) $)^{-1}$ day $^{-1}$, for the upper levels and the surface, respectively. Positive (negative) flux is the eastward (westward) flux of cyclones.

Fig. 10. Spatial distribution of the average meridional fluxes of cyclonic tracks passing over the eastern Mediterranean at surface and $500 \mathrm{hPa}$; contour interval is 0.0002 cyclones 
(deg.lat) $^{-1}$ day $^{-1}$. Positive (negative) flux is the northward (southward) flux of cyclones, respectively.

Fig. 11. Spatial distribution of the absolute ratio of average meridional fluxes over average zonal fluxes of cyclones passing over the eastern Mediterranean at surface and 500hPa. Open (full) circles indicate absolute ratio values smaller (greater) than one. 
Table 1 Relative frequency (\%) of the surface cyclones passing over the eastern

Mediterranean reaching each isobaric level

\begin{tabular}{lccccc}
\hline Level & $850 \mathrm{hPa}$ & $700 \mathrm{hPa}$ & $500 \mathrm{hPa}$ & $300 \mathrm{hPa}$ & $200 \mathrm{hPa}$ \\
\hline Relative frequency $(\boldsymbol{\%})$ & 92.7 & 89.8 & 82.8 & 75.1 & 64.8
\end{tabular}

Table 2 Relative frequency (\%) per month of the cold period of surface cyclones passing over the eastern Mediterranean reaching each isobaric level

\begin{tabular}{ccccccc}
\hline Level (mbar) & January & February & March & October & November & December \\
\hline $\mathbf{8 5 0}$ & 98.1 & 97.3 & 94.4 & 94.2 & 92.7 & 95.8 \\
$\mathbf{7 0 0}$ & 94.1 & 93.6 & 90.7 & 87.6 & 90.3 & 90.7 \\
$\mathbf{5 0 0}$ & 86.7 & 83.5 & 80.8 & 80.1 & 81.3 & 81.3 \\
$\mathbf{3 0 0}$ & 75.6 & 74.3 & 73.0 & 71.8 & 71.6 & 73.0 \\
$\mathbf{2 0 0}$ & 64.4 & 61.5 & 59.7 & 62.9 & 62.2 & 62.2 \\
\hline
\end{tabular}

Table 3 Relative frequency (\%) per origin sector of surface cyclones passing over the eastern Mediterranean reaching each isobaric level

\begin{tabular}{lrrrrr}
\hline Origin Domain & 850 mbar & 700 mbar & 500 mbar & 300 mbar & 200 mbar \\
\hline EM1 & 94.0 & 88.8 & 74.8 & 64.7 & 51.4 \\
EM2 & 95.1 & 88.8 & 79.5 & 67.9 & 56.2 \\
NE & 97.3 & 95.2 & 85.0 & 76.5 & 61.5 \\
NW & 93.7 & 93.3 & 91.7 & 86.7 & 80.4 \\
SW & 78.9 & 78.3 & 76.0 & 71.9 & 65.0 \\
W & 97.5 & 94.5 & 89.7 & 82.6 & 74.3 \\
\hline
\end{tabular}

Table 4 Relative frequency (\%) of surface cyclones for which a) the surface maximum deepening precedes the $500 \mathrm{hPa}$ counterpart, b) the surface maximum deepening follows the $500 \mathrm{hPa}$ counterpart and c) the maximum deepening occurs simultaneously at both levels, according to the origin sector

\begin{tabular}{lllr}
\hline & $\begin{array}{l}\text { surface preceding 500 } \\
\text { hPa }\end{array}$ & $\begin{array}{l}\text { surface following 500 } \\
\text { hPa }\end{array}$ & $\begin{array}{l}\text { simultaneous maximum } \\
\text { deepening }\end{array}$ \\
\hline EM1 & 54.5 & 34.4 & 11 \\
EM2 & 53.8 & 31.9 & 14.3 \\
NE & 52.2 & 38.9 & 8.8 \\
NW & 50.9 & 37.2 & 11.8 \\
SW & 57.6 & 30.1 & 12.2 \\
W & 64.4 & 27.9 & 7.6 \\
\hline
\end{tabular}


Table 5 Relative frequency (\%) of $500 \mathrm{hPa}$ counterparts of the EM surface tracks being located at each one of the tilting sectors, during the period that the tracks remain within the target area EM12

\begin{tabular}{|cccccccc|}
\hline SSW & WSW & WNW & NNW & NNE & ENE & ESE & SSE \\
\hline 9.2 & 16.8 & 28.5 & 31.7 & 8.1 & 4 & 0.8 & 0.8 \\
\hline
\end{tabular}

\section{APPENDIX 1}

Parameters of the vertical tracking algorithm specified for each isobaric level

\begin{tabular}{ccccccc}
\hline & SFC & $\mathbf{8 5 0} \mathbf{h P a}$ & $\mathbf{7 0 0} \mathbf{h P a}$ & $\mathbf{5 0 0} \mathbf{h P a}$ & $\mathbf{3 0 0} \mathbf{h P a}$ & $\mathbf{2 0 0} \mathbf{~ h P a}$ \\
\hline $\mathbf{a}$ & 0 & 0 & 0 & 0 & 0 & 0 \\
$\mathbf{z}$ & & 1457 & 3012 & 5574 & 9163 & 11774 \\
$\mathbf{z s m a x}$ & 1500 & 2457 & 4012 & 6574 & 10163 & 12774 \\
$\mathbf{z s r c}$ & 200 & 1657 & 3212 & 5774 & 9363 & 11974 \\
$\mathbf{r}_{\mathbf{d}}$ & 4 & 4 & 4 & 4 & 4 & 4 \\
$\mathbf{f}_{\mathbf{s}}$ & 2.25 & 1.9 & 1.5 & 1 & 1 & 1 \\
$\mathbf{c}_{\mathbf{1}}$ & 0.1 & 1 & 1 & 1 & 1 & 1 \\
$\mathbf{c}_{2}$ & 0.1 & 1 & 1 & 1 & 1 & 1 \\
$\mathbf{c}_{\mathbf{w}}$ & 0.1 & 5 & 5 & 5 & 5 & 5 \\
$\mathbf{r}$ & 1.2 & 1 & 0.9 & 0.7 & 0.46 & 0.34 \\
$\mathbf{R}$ search* & & 300 & 400 & 500 & 500 & 500 \\
\hline
\end{tabular}

a: orography gradient condition

$\mathbf{z}$ (in m): nominal/standard height

zsmax (in m): maximum topographic height for retaining the detected cyclones (zsmax $=\mathrm{z}+$ 1000 for the isobaric levels, while zsmax $=1500$ for surface cyclones)

zsrc (in m): topographic height for phasing down cyclone velocities from geopotential data $(\mathrm{zsrc}=\mathrm{z}+200$ for the isobaric levels, while $\mathrm{zsrc}=200 \mathrm{~m}$ for surface cyclones $)$

$\mathbf{r}_{\mathbf{d}}$ (in deg.lat): averaging radius for the calculation of steering velocities

$\mathbf{f}_{\mathrm{s}}$ : scaling factor for steering velocities 
$\mathbf{c}_{\mathbf{1}}$ (in $\mathrm{hPa}$ or $\mathrm{m} \mathrm{deg.lat^{-2 }}$ for surface and upper level cyclones, respectively): minimum area averaged laplacian for closed cyclones

$\mathbf{c}_{2}$ (in hPa or $\mathrm{m} \mathrm{deg.lat}{ }^{-2}$ for surface and upper level cyclones, respectively): minimum area averaged laplacian for open cyclones

$\mathbf{c}_{\mathrm{w}}$ (in $\mathrm{hPa}$ or $\mathrm{m}$ deg.lat ${ }^{-2}$ for surface and upper level cyclones, respectively): threshold of the area averaged laplacian for the characterization of a cyclone as strong

$\mathbf{r}\left(\right.$ in $\left.\mathrm{kg} \mathrm{m}^{-3}\right)$ : air density characteristic of level

$\mathbf{R}$ search (in $\mathrm{Km}$ ): searching radius (* the displayed values are referred to pairs of levels: MSLP-850 hPa, 850-700 hPa, 700-500 hPa, 500-300 hPa and 300-200 hPa). 


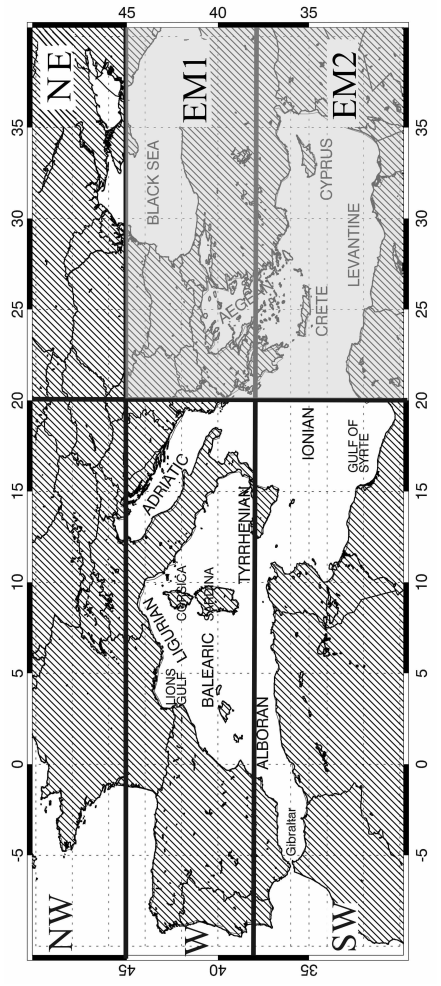




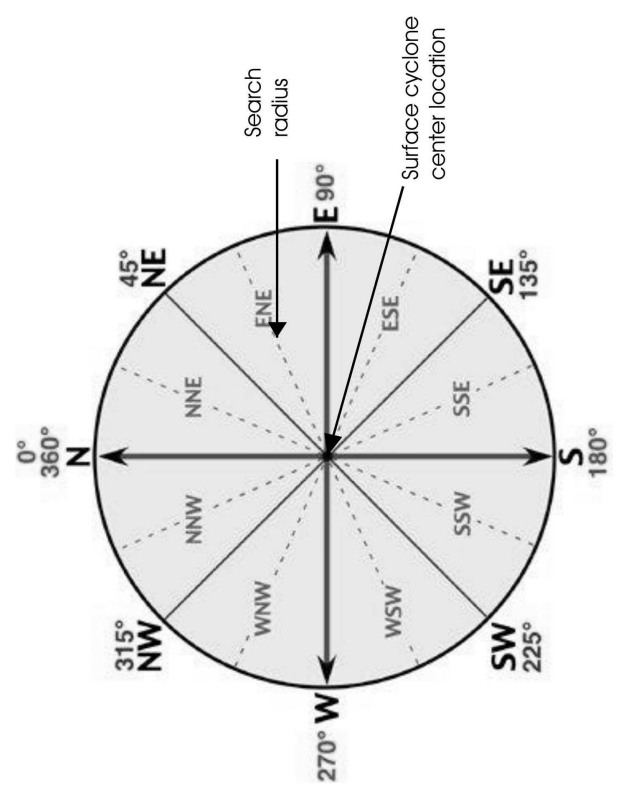









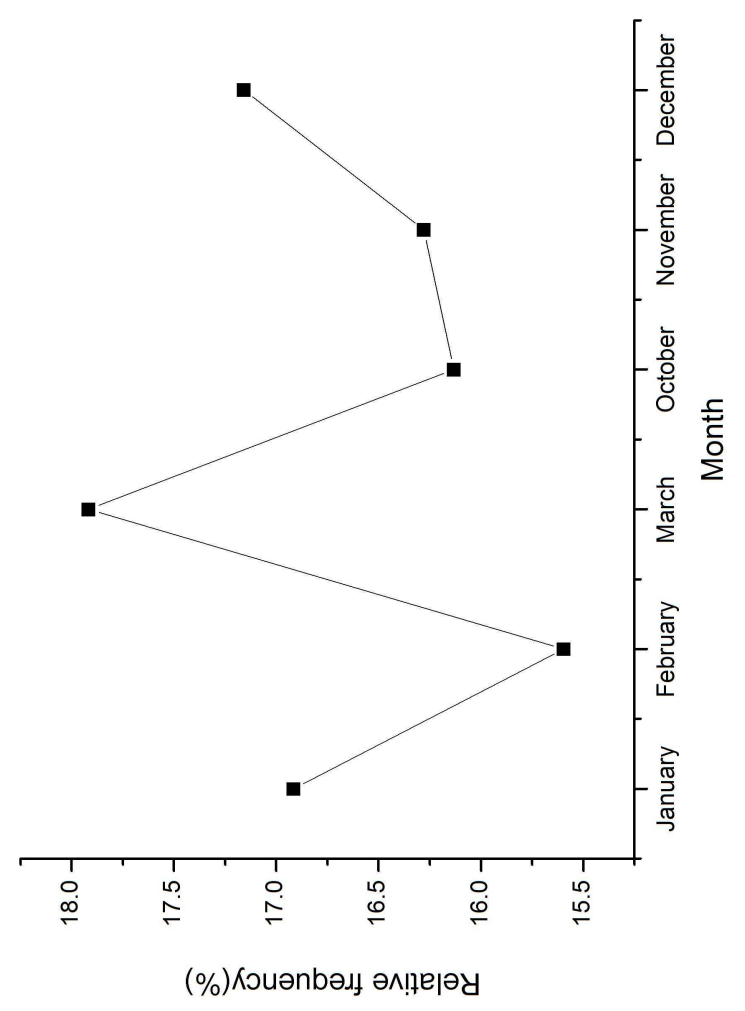




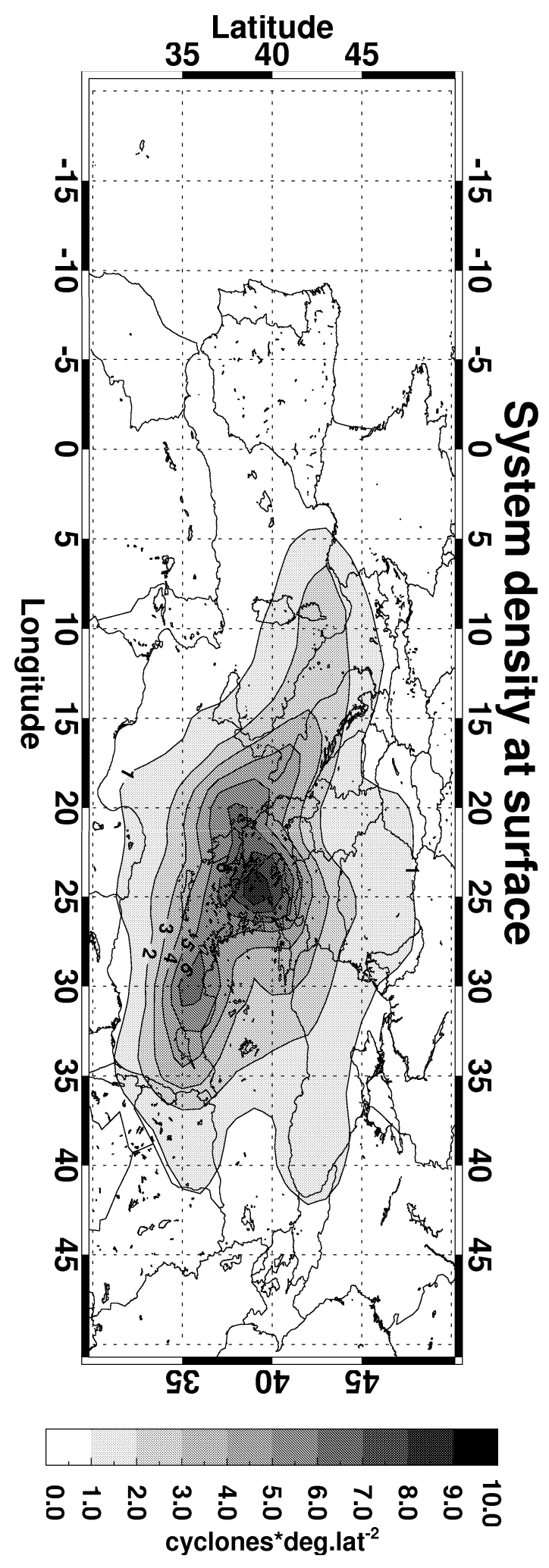




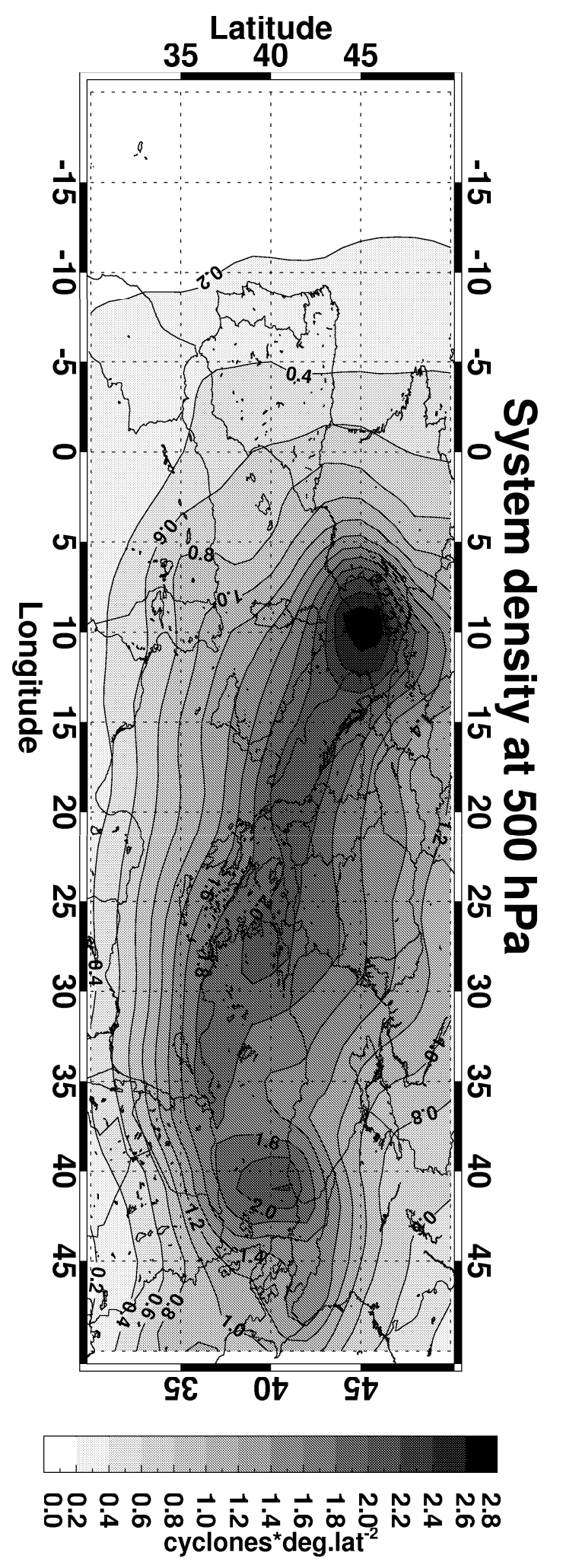




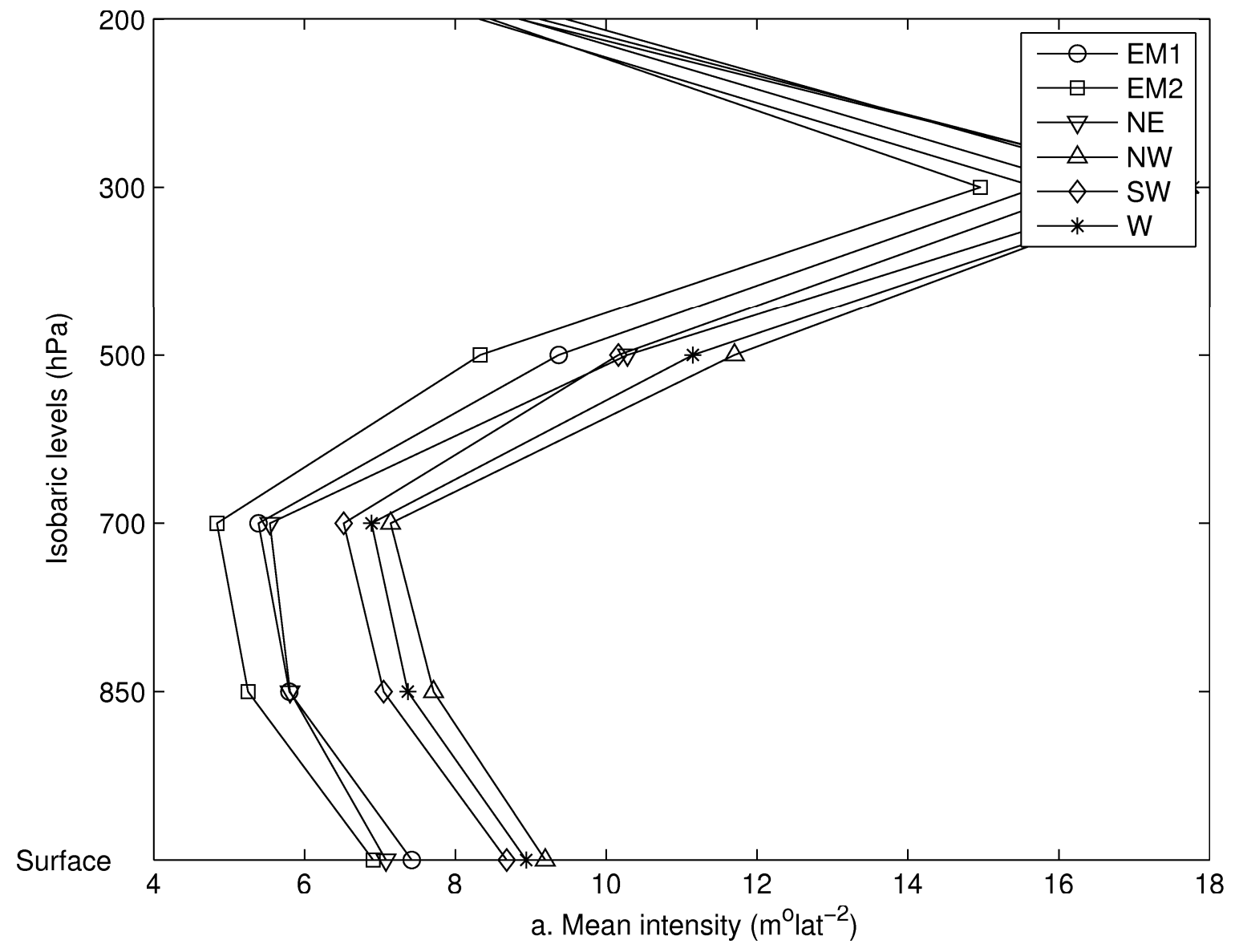




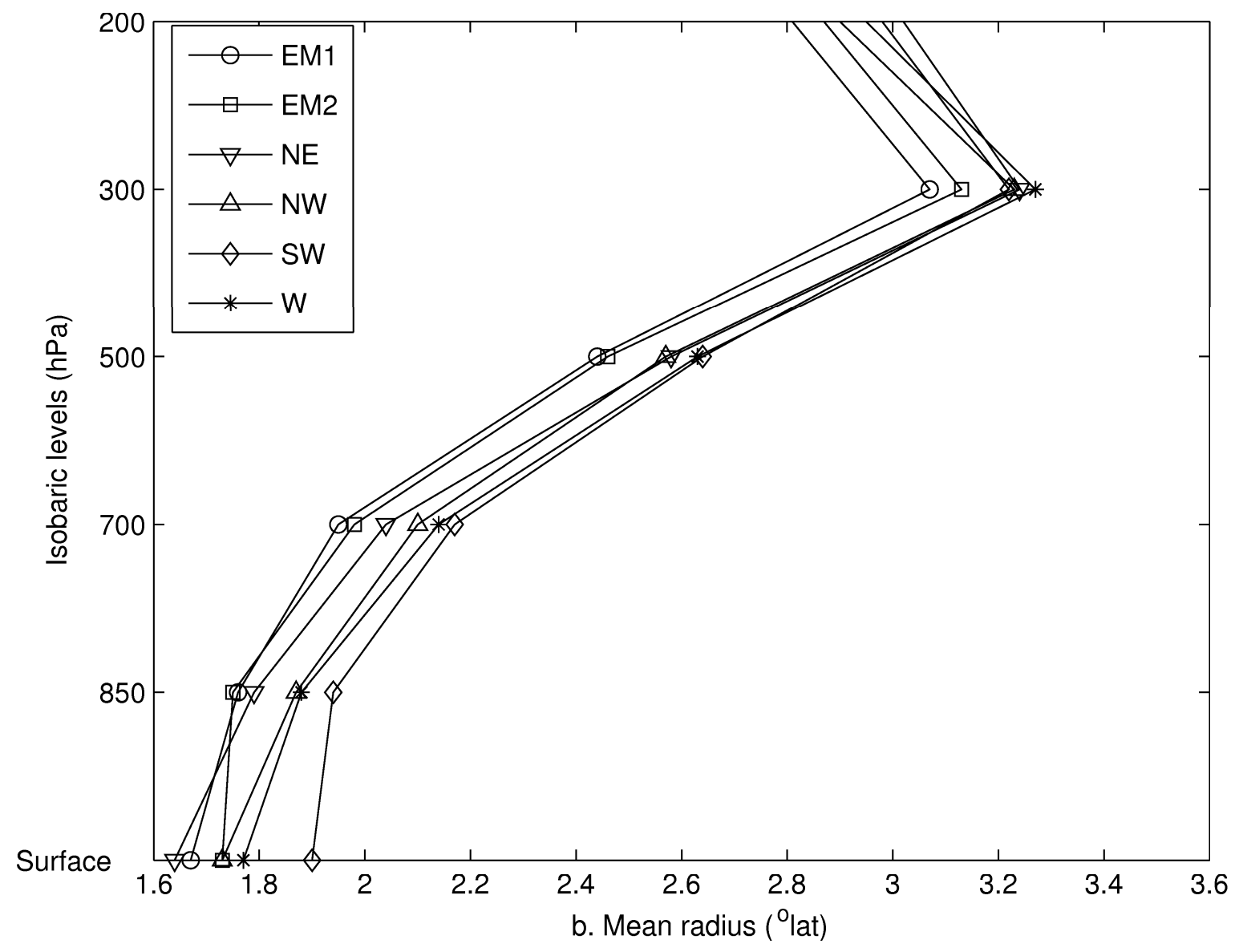




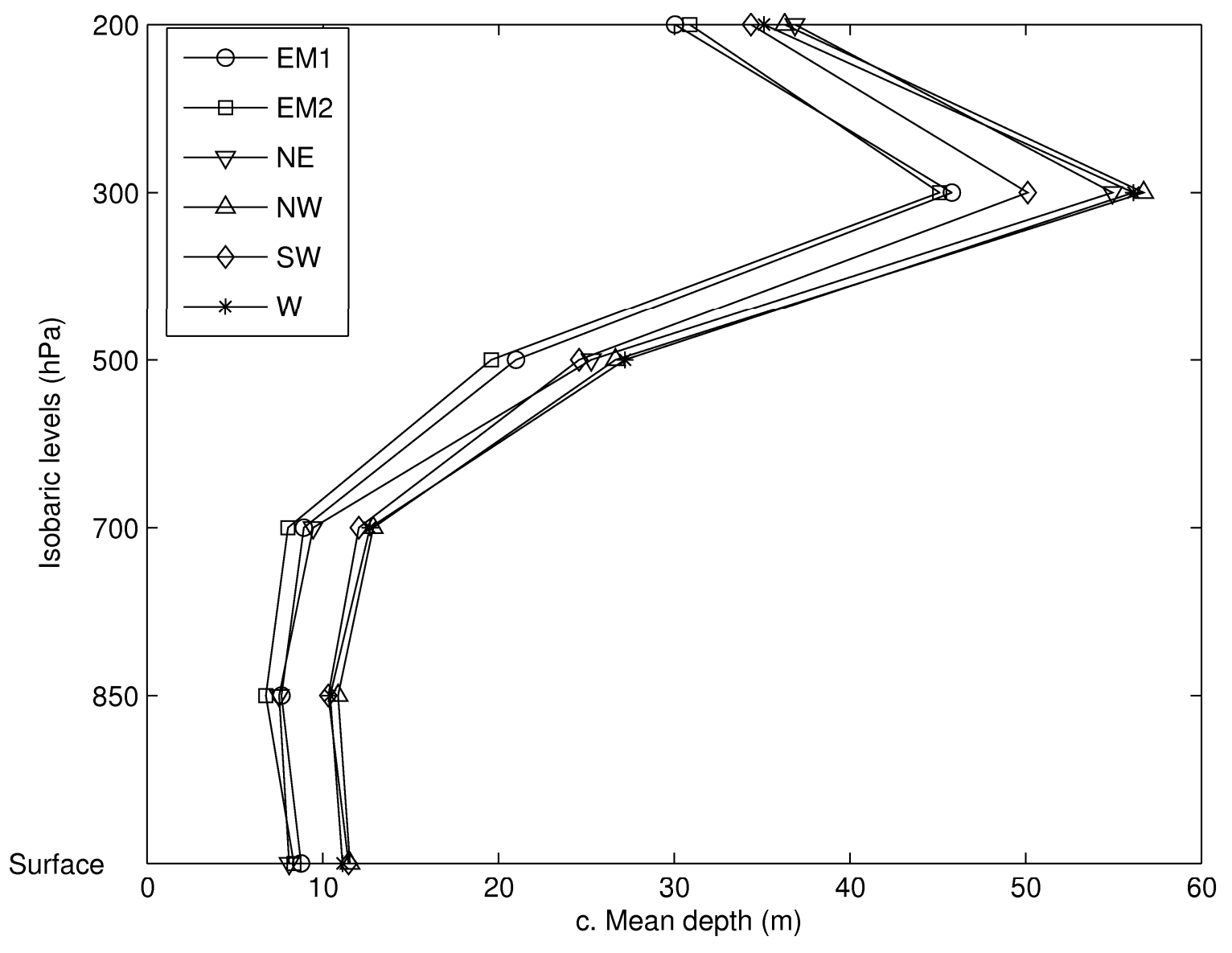




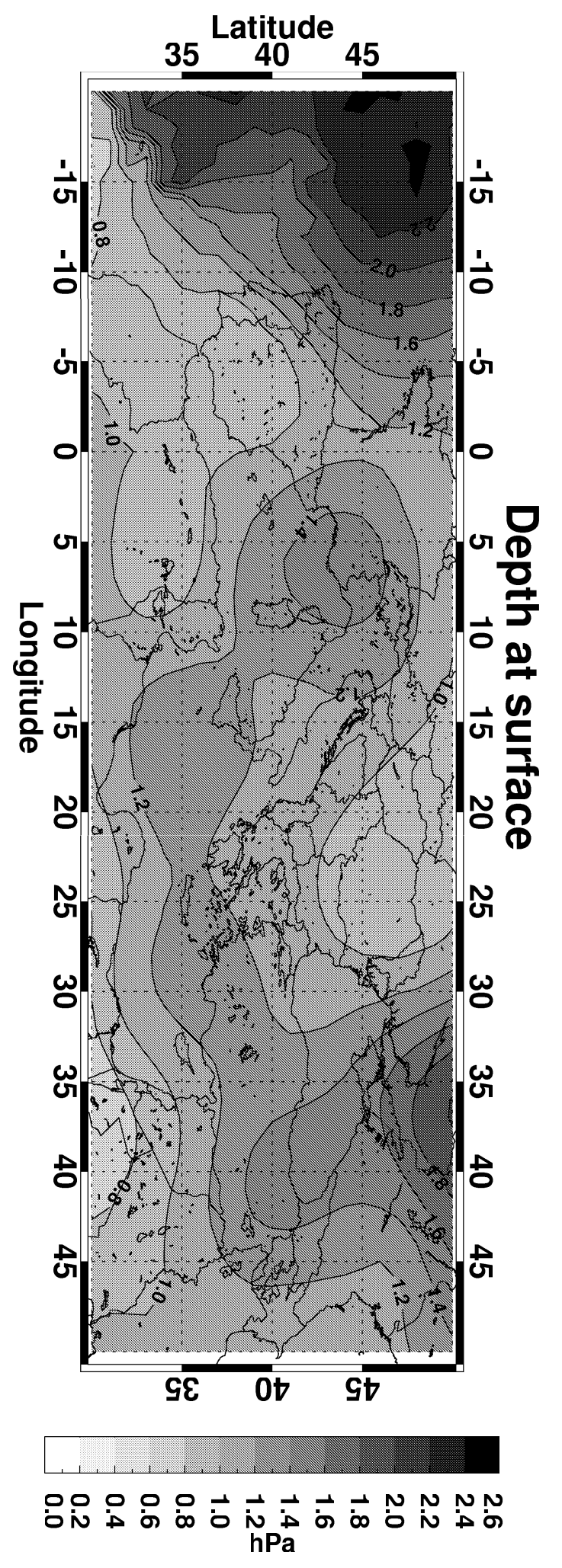




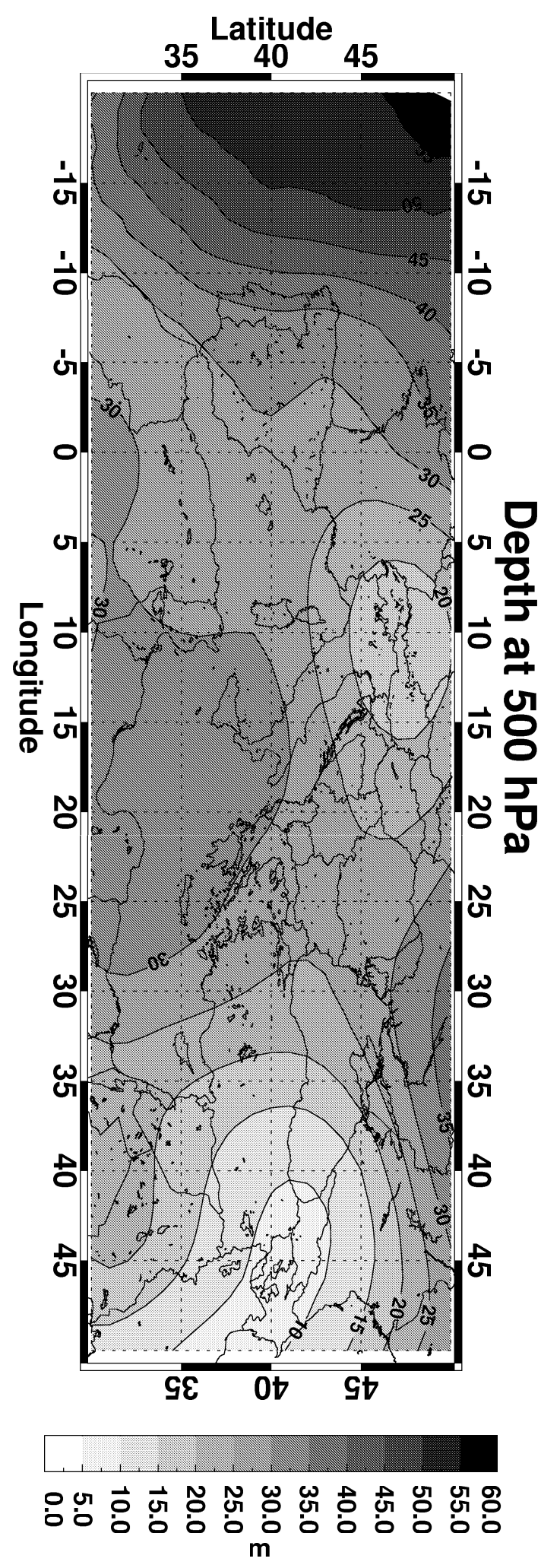




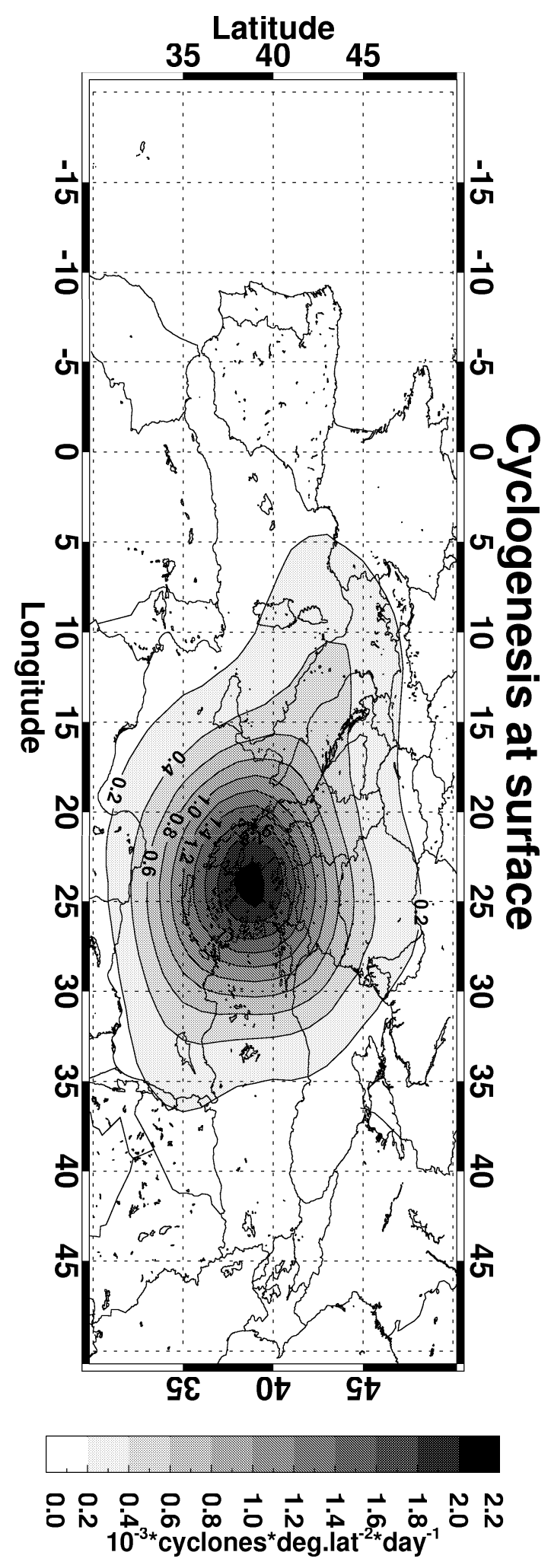









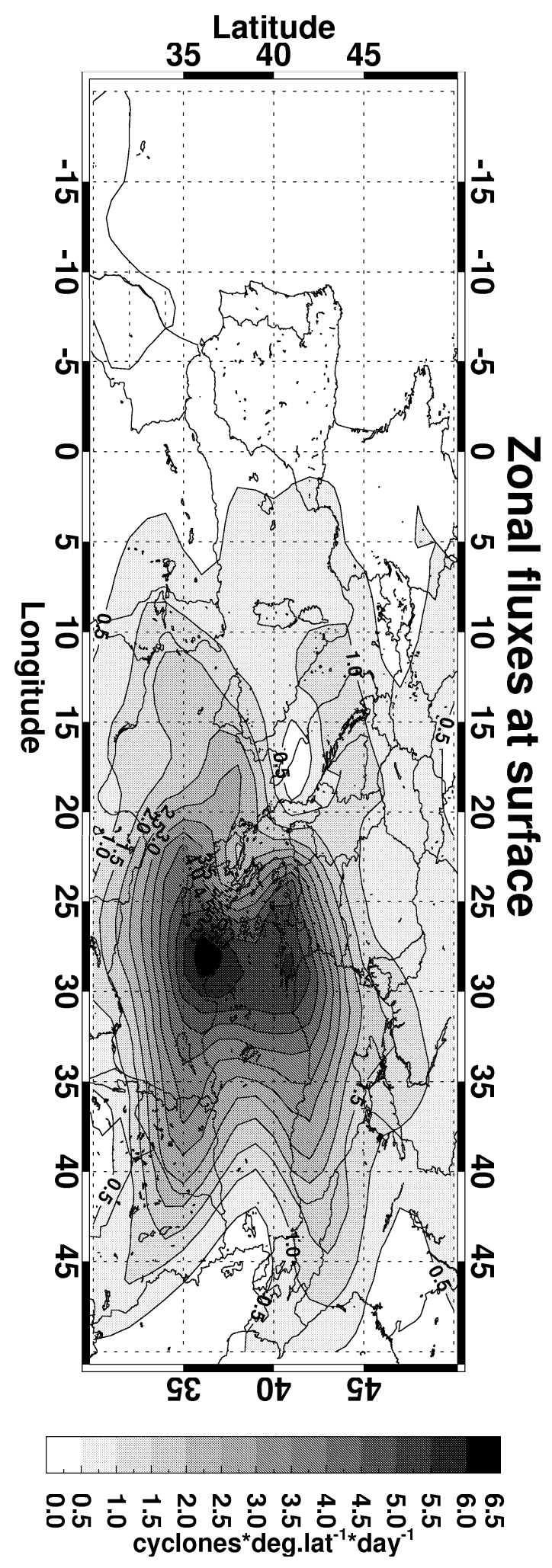




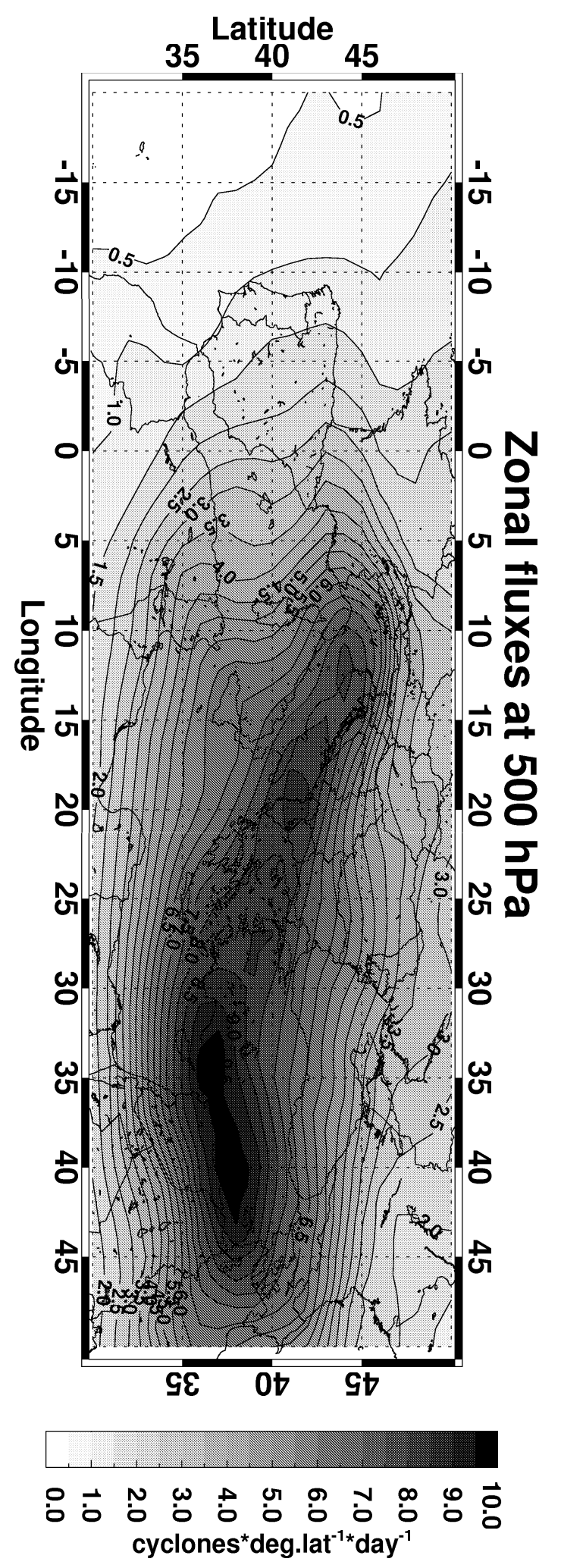









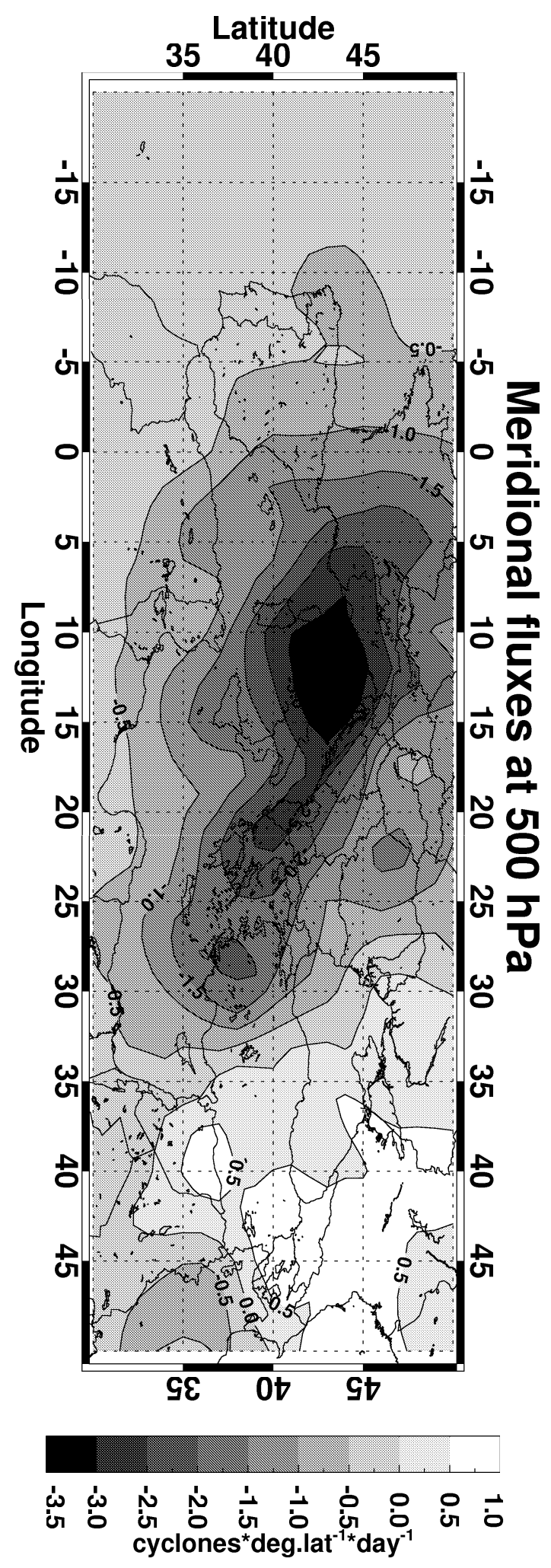


Ratio of meridional over zonal flux at surface

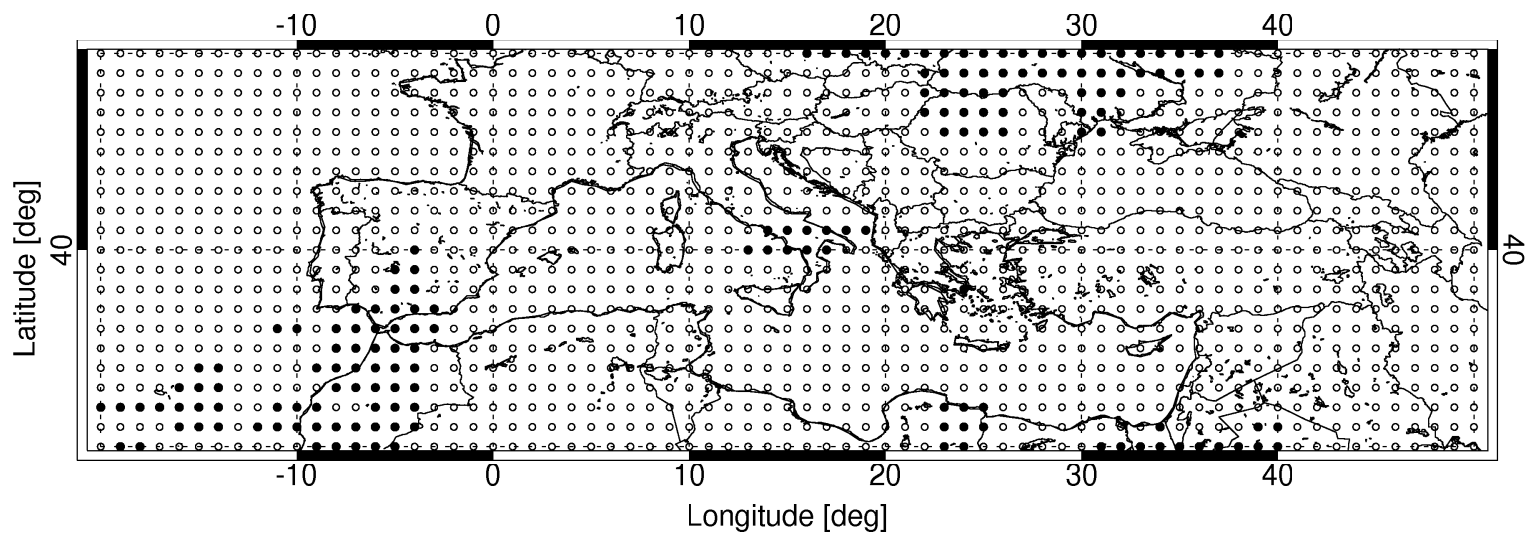


Ratio of meridional over zonal flux at $500 \mathrm{hPa}$

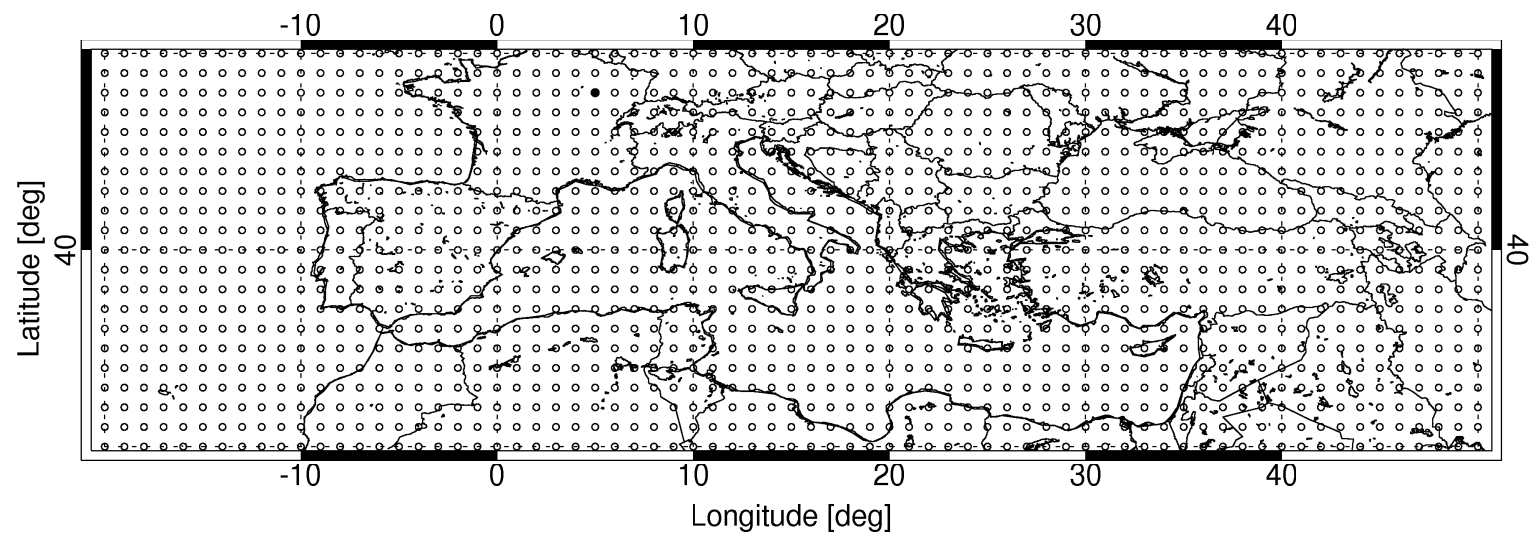




\section{University Library}

\section{- M M N E R VA A gateway to Melbourne's research publications}

Minerva Access is the Institutional Repository of The University of Melbourne

\section{Author/s:}

Flocas, HA;Kountouris, P;Kouroutzoglou, J;Hatzaki, M;Keay, K;Simmonds, I

Title:

Vertical characteristics of cyclonic tracks over the eastern Mediterranean during the cold period of the year

\section{Date:}

2013-05-01

\section{Citation:}

Flocas, H. A., Kountouris, P., Kouroutzoglou, J., Hatzaki, M., Keay, K. \& Simmonds, I. (2013). Vertical characteristics of cyclonic tracks over the eastern Mediterranean during the cold period of the year. THEORETICAL AND APPLIED CLIMATOLOGY, 112 (3-4), pp.375-388. https://doi.org/10.1007/s00704-012-0737-4.

Persistent Link:

http://hdl.handle.net/11343/282549 